\title{
The influence of ion beam rastering on the swelling of self-ion irradiated pure iron at
} $450^{\circ} \mathrm{C}$

Jonathan G. Gigax, Eda Aydogan, Tianyi Chen, Di Chen, and Lin Shao, Department of Nuclear Engineering, Texas A\&M University, College Station TX

Y. Wu, W.Y. Lo, and Y. Yang

University of Florida, Gainesville, FL 32611, USA

F. A. Garner

Radiation Effects Consulting, Richland WA

\begin{abstract}
Ion beam scanning or "rastering" is a technique that is frequently used to uniformly cover a larger specimen area during ion irradiation. In this study, we addressed the effects of rastered and defocused beams, using $3.5 \mathrm{MeV}$ iron ions to irradiate pure iron at $450^{\circ} \mathrm{C}$ to peak doses of 50 and $150 \mathrm{dpa}$. We focused on a frequency range relevant to pulsed fusion devices and show its importance to ion irradiation experiments used for simulating neutron damage. The beam was scanned at 15.6, 1.94, and $0.244 \mathrm{~Hz}$ and the resulting microstructure was compared with that produced by a non-rastered, defocused beam. At $150 \mathrm{dpa}$, the defocused beam case resulted in the highest observed void swelling of $\sim 12 \%$ at a depth of $\sim 700 \mathrm{~nm}$, a depth short of the peak dose position at $1000 \mathrm{~nm}$. The swelling at the peak dose position was significantly reduced by the defect imbalance phenomenon. A maximum swelling rate of $\sim 0.12 \% / \mathrm{dpa}$ was measured in this specimen at a depth of $600 \mathrm{~nm}$ below the ion-incident surface. Rastering led to much lower swelling levels achieved at significantly lower swelling rates, with the greatest rate of decrease occurring below $\sim 1 \mathrm{~Hz}$. Furthermore, the impact of the defect imbalance arising from interstitial injection and spatial distribution difference of initial interstitial and vacancy defects was strongly pronounced in the non-rastered case with a lesser effect observed with decreasing raster frequency.
\end{abstract}

Key words: void swelling, ion irradiation, pure iron, defect imbalance, injected interstitial, rastering

*Corresponding author at: 308 Bizzell East, Dept. of Nuclear Engineering, Texas A\&M University, College Station, TX 77843. Tel.: 979845 4107; fax: 979845 6443. Email address: 
1shao@tamu.edu

(L.Shao). 


\section{Introduction}

Void swelling of structural alloys is a life-limiting phenomenon of great importance for sustained performance of nuclear reactor components. This phenomenon causes volume changes, distortion, and changes in mechanical properties [1]. To study this phenomenon, ion irradiation is often used as a surrogate for neutron irradiation [2]. However, there are significant differences between ion and neutron irradiation, especially with respect to the spatial and temporal distribution of radiation damage, differences which lead to variations in void morphology, size, density and depth distribution. For neutron irradiation, there are essentially no gradients in dpa rate over dimensions comparable to grain sizes in metals, but there are two primary temporal regimes of interest. These are continuous, steady-state operation (i.e. fission reactors, Tokamak fusion reactors) and pulsed operation (i.e. inertial fusion reactors). In ion irradiation, however, spatial gradients can be very strong, often on sizes smaller than a typical grain diameter, and the ion irradiation can use either a continuous, defocused beam or a focused and scanned beam, the latter often referred to as "rastering".

In order to irradiate a relatively large area compared to the ion beam diameter, beam rastering is often performed. However, ASTM E521-77 [3] strongly suggests using a defocused beam rather than a scanned beam to simulate void swelling arising from steady-state neutron irradiation. A phenomenon, often referred to as void throttling, can occur at high temperatures whereby very small void nuclei formed at a given location during the beam-on period dissolve in the longer beam-off period before the beam returns. This suggestion, however, is based on a limited set of early (1970's) experiments on pure nickel [4-6] and therefore requires additional investigation before accepting it as a universal proscription against ion beam rastering for simulation of neutron-induced void swelling behavior.

It should be noted that void nucleation is known to be very sensitive to environmental variables such as rastering, much more so than radiation-induced segregation, changes in mechanical properties, and changes in various physical properties. Thus, the ASTM E521-77 recommendation to avoid ion beam rastering is not necessarily meant to apply to any other property changes. The current work addresses the impact of rastering at relatively low 
frequencies on void swelling in pure iron, which was used as a model surrogate material for more complex ferritic alloys to be studied in later irradiations. In this experiment, a limited ranged of low rastering frequencies relevant to pulsed fusion devices was used to produce void swelling and the results were compared with that produced by a steady-state, non-rastered, defocused beam.

\section{Experimental details}

Samples were sectioned from a pure iron bar (99.99\%, Sigma-Aldrich) to produce disks of size $4 \mathrm{~mm} \times 4 \mathrm{~mm} \times 0.5 \mathrm{~mm}$. These disks were mechanically polished on a Dace Technologies Nano 2007 polisher using successive grits of 600, 800, and 1200 silicon carbide paper. The samples were further polished using $1 \mu \mathrm{m}$ and $0.05 \mu \mathrm{m}$ alumina solutions. After mechanical polishing, the samples were electropolished using a 6\% perchloric and $94 \%$ acetic solution for 10 seconds to remove all residual surface damage arising from mechanical polishing. The specimens were then inspected using a scanning electron microscope to ensure an undamaged surface.

The specimens were mounted on an electrically-heated copper stage and good thermal contact was maintained using silver paste. These specimens were brought to a temperature of $450^{\circ} \mathrm{C}$ measured using thermocouples mounted to the stage. Independent measurements were performed to verify that the beam heating arising from either a defocused or a rastered beam was relatively low. Since most published modeling studies on pulsing and rastering focus only on isothermal conditions, care was taken to separate temporal changes in dpa rate from concurrent changes in temperature during the beam-off and beam-on periods.

The procedure used a FLIR infrared (IR) camera collecting data at 30 frames per second. Initial calibration of the sample emissivity involved matching the temperature of the stage, as measured by the thermocouple, was performed prior to commencing ion bombardment. The temperature was then monitored by the IR camera during ion bombardment and the beam heating calculated by taking the difference of the sample temperature before and during ion bombardment. Thermally conductive samples (i.e. pure iron and graphite) exhibited a maximum temperature rise of $2-3^{\circ} \mathrm{C}$ for the defocused case and $4-6^{\circ} \mathrm{C}$ increase for the raster case. This 
demonstrates that the temperature rise from the two beam configurations is not substantial. Additionally, the beam uniformity was assessed using the temperature map produced by the IR camera. When compared to previous results obtained using other conventional methods, such as an optical mapping from a scintillator and a low dose Kapton implantation, the IR-derived temperature distribution shows good agreement with the uniformity established by these methods.

Iron ion irradiation was performed by using a $1.7 \mathrm{MV}$ tandem accelerator with an energy of 3.5 MeV, producing peak damage levels at $1000 \mathrm{~nm}$ below the surface of 50 and $150 \mathrm{dpa}$, as calculated using the Kinchin-Pease option of the SRIM-2013 code [7] as recommended by Stoller and coworkers [8]. There was no gas co-injection employed in this study. The beam current was limited to $200 \mathrm{nA}$ over an area of $36 \mathrm{~mm}^{2}$, yielding a time-averaged dpa rate of 1.74 $\mathrm{x} 10^{-3} \mathrm{dpa} / \mathrm{s}$, varying less than $5 \%$ over the duration of the experiment. Beam conditions are listed in Table 1 for all four beam conditions. The beam spot size for the defocus case was chosen to be $6 \mathrm{~mm} \times 6 \mathrm{~mm}$. The configuration for the defocus case involved using an electrostatic quadruple to produce a uniform beam over the desired area. To simplify the analysis, the beam involved one-dimensional rastering rather than the frequently used twodimensional raster method.

The beam size for the raster case was $2.5 \mathrm{~mm} \times 4 \mathrm{~mm}$ and was scanned over an area of 9 $\mathrm{mm} \times 4 \mathrm{~mm}$, larger than the specimen size to ensure that all areas were irradiated uniformly. The ion beam was rastered using a Physicon Model RS1200 with a horizontal raster speed at 0.244, 1.93, and $15.625 \mathrm{~Hz}$. The irradiated samples were characterized by cross sectional transmission electron microscopy (TEM), with specimen preparation accomplished using the focused-ionbeam (FIB) based lift-out technique. Microstructural analysis was performed using a FEI Tecnai G2 F20 instrument, operated at $200 \mathrm{kV}$.

\section{Results}

Figures 1a-1d show TEM micrographs of 50 dpa (peak) specimens obtained with a rastering beam at frequencies of $15.63 \mathrm{~Hz}, 1.95 \mathrm{~Hz}, 0.244 \mathrm{~Hz}$, and with a defocused beam, respectively. With decreasing rastering frequencies, void sizes tend to be smaller and densities higher. In 
comparison, defocusing results in larger voids. However, we note that, in all cases, voids formed with octahedral-like shapes as deduced from the observed square and hexagon shaped void projections predicted by the Wulff construction theory [9]. Figures 2a-2d show TEM micrographs of 150 dpa specimens. The observed trends in void density, sizes, and shapes at 150 dpa (peak) are consistent with observations from the 50 dpa experiments.

For a better comparison of the void swelling at $50 \mathrm{dpa}$, depth-dependent void swelling profiles were divided into two groups. Figure 3 compares the $15.63 \mathrm{~Hz}$ and $1.95 \mathrm{~Hz}$ rastering frequency, and Figure 4 compares $0.244 \mathrm{~Hz}$ raster and defocused beam conditions. One general trend is that with decreasing frequencies, the void distributions reach deeper into the specimen. For the lowest frequency, $0.244 \mathrm{~Hz}$, the void distribution extends beyond that produced by a defocused beam. The "spikeness" of the swelling vs. depth profiles is an artifact of the relatively low number of voids and the choice of sampling statistics. Note that only a few voids were found in the 50 dpa specimen beyond $\sim 650 \mathrm{~nm}$ depth in the defocus case, most likely resulting from the strong influence of the injected interstitial to suppress both void nucleation and subsequent growth $[10,11]$. In the rastered cases there is a progressive shortening of the voided region, moving back from 1000 to 600 to $300 \mathrm{~nm}$ as the rastering frequency increases from 0.244 to 1.95 to $15.63 \mathrm{~Hz}$.

Figures 5 and 6 show the depth profiles of void swelling for the defocused and $15.63 \mathrm{~Hz}$ cases for $50 \mathrm{dpa}$ and $150 \mathrm{dpa}$, respectively. The void depth profiles are superimposed on the normalized SRIM-calculated dpa and injected interstitial profiles. Note that at $150 \mathrm{dpa}$, voids reach deeper into the sample compared to the 50 dpa case as void nucleation at the higher dose progressively overcomes the defect imbalance effect [11]. In both cases however, void swelling is suppressed in the peak dpa region.

Also shown in Figures 5 and 6, there is a strong change in SRIM-calculated dose rate from the ion-incident surface to the peak dose position, increasing by a factor of $\sim 3.7$. In order to determine an unperturbed swelling rate between the 50 and 150 peak dpa cases without introducing differences in dpa rate, it is necessary select a depth for analysis that minimizes the influence of the specimen surface and also avoids the defect imbalance suppression zone. 
Therefore, swelling data was taken from the depth of $600 \mathrm{~nm} \pm 100 \mathrm{~nm}$, where the average dose is only $\sim 63 \%$ of the peak value. Thus, data was actually measured at 32 and 96 dpa rather than at 50 and $150 \mathrm{dpa}$. The void characteristics and swelling are presented in Table 2. Although our studies are limited to two dpa values only and therefore preclude the possibility of observing non-linear swelling, the observed large differences in average swelling rate between the defocused and rastered cases are consistent. Clearly, rastering tends to suppress the void swelling rate, even when the injected interstitial effect is minimized.

In Fig. 5, a peak swelling of $\sim 12 \%$ at $\sim 700 \mathrm{~nm}$, along with a swelling of $\sim 9 \%$ at a depth of $600 \mathrm{~nm}$ (corresponding to $96 \mathrm{dpa}$ ), was observed in the defocused irradiation, but the rasteringproduced swelling levels are significantly lower at the same depths. As shown in Fig. 6, the void densities at both 50 and 150 dpa irradiations are lowest for the $15.63 \mathrm{~Hz}$ case, but all show a monotonic increase from 32 to $96 \mathrm{dpa}$. Overall, the depth-dependent swelling behaviors are complicated. As shown in Figure 7, the highest swelling rate of $\sim 0.12 \%$ per dpa is obtained from a defocused beam, while all rastering cases lead to significantly lower swelling values, decreasing with increasing rastering frequency. Furthermore, rastering at relatively low frequencies decreases the swelling rate quickly, with a more gradual rate of decrease occurring beyond $\sim 1 \mathrm{~Hz}$.

\section{Discussion}

There are two very significant observations resulting from this study. First, in pure iron there is a strong suppression of void nucleation and growth in the region where the peak dpa and the injected interstitial overlap. At higher doses the suppression effect is overridden somewhat but is never completely overcome. This behavior was observed not only in this study but in a previous study in the current experimental series [11]. Both the present study and the previous work suggest that the swelling suppression effect requires that microstructural data be extracted from a depth removed as far as possible from the injection zone. The defect imbalance effect [11], and previously reported injected interstitial effect [10, 12-19], are known to suppress both void nucleation and void growth near the end of the ion range. 
Our previous work has shown that the suppression effect arises from two contributions [11]. The first is that extra atoms are implanted into the material at the projected range, which increases the local interstitial population over that of the vacancy population. The other contribution comes from the small spatial distribution difference between vacancies and interstitials produced during the knock-on process in ion irradiation using a collimated beam. Although in damage cascade creation, the knock-on directions appear to be random, statistical analysis shows that, overall, the knock-on interactions favor momentum transfer in the forward direction, which leads to interstitial distributions slightly deeper than that of vacancies. This results in a vacancy-rich near-surface region and an interstitial-rich region near the end of range. These differences in spatial distribution lead to a dramatic suppression of void swelling near the end of ion range. As the accumulated dose increases, these influences are overcome somewhat and the void distribution pushes deeper but not completely into the full ion range. This phenomenon was also observed in a study by Kuramoto and coworkers who showed that there was a strong but not total reduction of void swelling in pure iron close to the ion deposition range, with the complication that Kuramoto used nickel ions rather than iron ions, introducing some chemical alteration in the injected region [20].

Second, it is very clear that rastering decreases the average swelling rate over the 32-96 dpa range, but there may be synergisms with other variables that were not revealed in this study. Such synergisms are suggested by the extension of the void range when going from defocused to $0.244 \mathrm{~Hz}$, followed by a steady reduction in void range at higher rastering frequencies. Therefore it appears that the rastering and defect imbalance suppression effects may interact, suggesting the possibilities of more complicated dependencies at temperatures other than the $450^{\circ} \mathrm{C}$ employed in this study.

To provide an explanation of the underlying phenomenon involved in rastering we rely on the treatment of Ghoniem and Kulcinski [21] and Simonen [22] that showed a significant difference between pulsed beam parameters and the resultant void swelling. The modeling was based on the defect interactions with existing void nuclei. In metals, interstitials are faster diffusing than vacancies. Further, in pure Fe with large grains, vacancy recombination with interstitials is the dominant interaction mechanism. During pulsed irradiation, interstitials are 
initially the primary component of the defect flux migrating towards the void nuclei, and cause their shrinkage. After a majority of the interstitials have diffused, the remaining vacancies diffuse towards and into the nuclei and thereby cause their growth. If there is a long duration between pulses, then voids begin to shrink due to vacancy emission at the void surface. Furthermore, if another pulse is introduced before significant vacancy diffusion occurs, the preexisting void nuclei will shrink further. This theory agrees with our observations that higher rastering frequencies lead to lower void swelling.

On the other hand, we need to point out an additional complexity which was not considered in the previous modeling studies. First, if stable void nuclei have already formed prior to pulsed irradiation, the effect will not be as pronounced. The previous studies assumed the existence of void nuclei prior to the irradiation. Full scale modelling is required to account for the impact of pulsing on void nucleation. Second, the existence of strong defect sinks, such as deformationinduced dislocation networks, high densities of precipitates or a high density of nanostructured grain boundaries, may alter the defect flux towards the voids, and subsequently affect the overall stability of void nuclei as a result of competition with these other defect sinks. Third, when defect imbalance or injected interstitials are included into the picture, enhanced vacancy concentrations near the surface and enhanced interstitial concentrations near the projected range will further complicate the pulsing or rastering effect.

Within the limited accuracy associated with only two data points, our observed swelling rate of $\sim 0.12 \% / \mathrm{dpa}$ for the defocused beam case for pure iron may or may not be consistent with the swelling rate of $\sim 0.2 \%$ dpa observed in neutron irradiated $\mathrm{Fe}-\mathrm{Cr}$ binary alloys [23, 24]. It is probably unrealistic, however, to expect that pure iron and iron-chromium alloys must exhibit the same swelling rate. Several neutron irradiation studies have shown that chromium additions to pure iron initially cause a strong decrease of swelling [25-27], and one study showed that cold-worked pure iron swelled $\sim 6 \%$ at only 3 dpa [28], a swelling rate of $\sim 0.5 \% / d p a$. In general, the available data shows that swelling in neutron irradiated pure iron is accelerated by cold-work and is also accelerated by irradiation at lower dpa rates [24-28]. For instance, Kuramoto notes that $\sim 0.3 \%$ swelling was attained at $\sim 1 \mathrm{dpa}$ in the JMTR reactor at $450^{\circ} \mathrm{C}$, but the rather large 
uncertainty on his quoted dose level precludes a confident statement that his swelling rate was $0.3 \% / d p a[20]$.

Finally, the applicability of our results to other irradiation conditions is constrained by two limitations. First we irradiated at only one temperature and the behavior might change at other temperatures. Simonen [22] notes that as the temperature is increased near the peak swelling temperature, the difference in void swelling for raster speeds becomes larger, decreasing at temperatures beyond the peak void swelling temperature. Second, it should be noted that our studies utilized relatively low rastering frequencies characteristic of pulsed fusion devices. However, many current ion irradiation facilities use rastering at frequencies ranging from 200 to $2500 \mathrm{~Hz}$. If we extrapolate the very slow rate of decline in swelling rate beyond $\sim \mathrm{Hz}$ shown in Figure 7 to such high frequencies, it appears that the swelling rate might saturate at a rather low value.

Getto et. al. performed a raster-no raster comparison on $\mathrm{HT} 9$ at $440^{\circ} \mathrm{C}$ to 140 dpa that support the possibility of rastering-induced void suppression at higher frequencies [30]. Ion beam rastering was performed at $1061 \mathrm{~Hz}$ in the vertical direction and $255 \mathrm{~Hz}$ in the horizontal direction, with the results compared to those produced using a defocused non-rastered beam. No voids were seen in the rastered specimen with zero or 10 appm helium preinjection, and a rather low density of small voids was seen with 100 appm helium preinjection. However, in the no raster, defocused beam condition voids were seen at larger sizes and significant densities in the specimens with 0, 10 and 100 appm helium preinjection levels, showing that, in the absence of helium, rastering completely suppresses void nucleation under these irradiation conditions.

However, previous modelling [22] suggests that increasing the raster frequency to high speeds should result in void swelling similar to that of a non-rastered, defocused beam. As noted previously, however, the applicability of this model to experimental results is not clear. At this time, however, we have no confidence that our results can be extrapolated to such higher frequencies. Therefore, the next round of studies will explore this frequency regime. Additionally, at this time, our results are considered to be only applicable to pure iron and should 
not be extrapolated to more complex alloys. Further studies are required to explore such extrapolations.

\section{Conclusions}

This study clearly shows that a significant effect of rastering frequency operates on void nucleation and growth in self-ion irradiated pure iron at $450^{\circ} \mathrm{C}$, with rastering leading to reduction of swelling in comparison with irradiation using a defocused, static beam. When compounded with the defect imbalance effect there is a significant suppression of swelling with the net effect varying with depth from the ion-incident surface. In order to confidently use ion bombardment as a surrogate technique to replace neutron irradiation, it appears that a defocused beam should be used. The results of this study therefore support the no-raster recommendation of ASTM E521-77 in simulating neutron damage using ion bombardment.

\section{Acknowledgements}

The research was supported by US Department of Energy, NEUP program, through grant no. DE-NE0008297. 


\section{References}

1. F. A. Garner, "Radiation Damage in Austenitic Steels", in Konings, R.J.M., (ed.) Comprehensive Nuclear Materials, volume 4, (2012) pp. 33-95, Elsevier.

2. G. S. Was, (2007). Fundamentals of Radiation Materials Science: Metals and Alloys, Springer.

3. ASTM E521, 2009, "Standard Practice for Neutron Radiation Damage Simulation by Charged-Particle Irradiation," ASTM International, West Conshohocken, PA, DOI: 10.1520/E0521-96R09E01, www.astm.org

4. J. A. Sprague, F. A. Smidt, Jr., J. E. Westmoreland and P. R. Malmberg, NRL Memorandum 2555 (1972).

5. J. A. Sprague and F. A. Smidt. NRL Memorandum 2692 (1972).

6. A. Taylor, D.I. Potter, and H. Wiedersich. ANL/CTR/TM-39, Argonne National Laboratory (1975).

7. J. F. Ziegler, M. D. Ziegler, J. P. Biersack. Nucl. Instr. Meth. Phys. Res. B 268 (2010) 1818-1823.

8. R. E. Stoller, M. B. Toloczko, G. S. Was, A. G. Certain, S. Dwaraknath, and F. A. Garner. Nucl. Instr. Meth. Phys. Res. B 310 (2013), 75-80.

9. G. Wulff. Zeitschrift fur Krystallographie und Mineralogie. 34 (1901) 449-530.

10. F.A. Garner. J. Nucl. Mater. 117 (1983), 177-197.

11. L. Shao, C.-C. Wei, J. Gigax , A. Aitkaliyeva, D. Chen, B. H. Sencer, F. A Garner. J. Nucl. Mater. 453 (2014) 176-181.

12. D. L. Plumton and W. G. Wolfer. J. Nucl. Mater. 120 (1984) 245-253.

13. E. H. Lee, L. K. Mansur, and M. H. Yoo. J. Nucl. Mat. 85 \& 86, 577 (1979).

14. D. L. Plumton, G. L. Kulcinski. J. Nucl. Mat. 133 \& 134, 444 (1985).

15. L. K. Mansur and M. H. Yoo. J. Nucl. Mater. 85 \& 86 (1979) 523-532.

16. D. B. Bullen, G. L. Kulcinski and R. A. Dodd. Nucl. Instr. Meth. Phys. Res. B 10/11 (1985) 561-564.

17. J. B. Whitley, G. L. Kulcinski, P. Wilkes, H. V. Smith Jr. J. Nucl. Mater. 79 (1979) 159169.

18. D. L. Plumton, H. Attaya, W. G. Wolfer. J. Nucl Mater. 122 \& 123 (1984) 650-653.

19. A. D. Brailsford and L. K. Mansur. J. Nucl. Mater. 71 (1977) 110-116. 
20. E. Kuramoto, et al. J. Nucl. Mater. 103 (1981) 1091-1096

21. N. Ghoniem and G. L. Kulcinski. J. Nucl. Mater. 69-70 (1978) 816-820.

22. E. P. Simonen, N. M. Ghoniem, and H. K. Packan. J. Nucl. Mater. 122 \& 123 (1984) 391-401.

23. B. H. Sencer, F. A. Garner. J. Nucl. Mater. 283-287 (2000) 164.

24. F. A. Garner, M. B. Toloczko and B. H. Sencer. J. Nucl. Mater. 276 (2000) 123-142.

25. S. I. Porollo, A. M. Dvoriashin, A. N. Vorobyev, Yu. V. Konobeev. J. Nucl. Mater. 256 (1998) 47-253.

26. Yu. V. Konobeev, A. M. Dvoriashin, S. I. Porollo, and F. A. Garner. J. Nucl. Mater. 355 (2006) 124-130.

27. E. A. Little, D. A. Stow, in Proc. Int. Conf. on Irradiation Behaviour of Metallic Materials for Fast Reactor Core Components, Ajaccio, France 1979, pp. 17-24.

28. A. M. Dvoriashin, S. I. Porollo, Yu. V. Konobeev and F. A. Garner. J. Nucl. Mater. 283287 (2000) 157-160.

29. N. I. Budylkin, E. G. Mironova, V. M. Chernov, V. A. Krasnoselov, S. I. Porollo and F. A. Garner. J. Nucl. Mater. 375 (2008) 359-364.

30. E. Getto, Z. Jiao, A.M. Monterrosa, K. Sun, G.S. Was, J. Nucl. Mater., (2015) accepted pending revisions. 


\section{Captions}

Figure 1 - Micrographs of void swelling for irradiation to 50 peak dpa in pure iron for rastered beams at. (a) $15.63 \mathrm{~Hz}$, (b) $1.95 \mathrm{~Hz}$, (c) $0.244 \mathrm{~Hz}$, and a (d) defocused beam. Length of the scale bar is $250 \mathrm{~nm}$. Dashed lines mark the surface and the incident ion range with the incident ion direction normal to the surface.

Figure 2 - Micrographs of void swelling for irradiation to 150 peak dpa in pure iron for rastered beams at (a) $15.63 \mathrm{~Hz}$, (b) $1.95 \mathrm{~Hz}$, (c) $0.244 \mathrm{~Hz}$, and with a (d) defocused beam condition. Length of the scale bar is $250 \mathrm{~nm}$.

Figure 3 - Comparison of depth dependent swelling for 50 peak dpa irradiation with raster beam frequencies of $15.63 \mathrm{~Hz}$ and $1.95 \mathrm{~Hz}$. Swelling data represented by each bar averaged over a 50 nm depth.

Figure 4 - Comparison of depth-dependent swelling for 50 peak dpa irradiation with defocused beam and raster beam frequency of $0.244 \mathrm{~Hz}$. Swelling data represented by each bar averaged over a $100 \mathrm{~nm}$ depth.

Figure 5 - Comparisons of depth-dependent swelling from a defocus beam for 50 and 150 peak dpa. Profiles of dpa and Fe implanted ion distributions from SRIM calculation are plotted for comparison.

Figure 6 - Comparisons of depth-dependent swelling from a $15.63 \mathrm{~Hz}$ rastering beam for 50 and 150 peak dpa. Profiles of dpa and Fe implanted ion distributions from SRIM calculation are plotted for comparison.

Figure 7 - Void swelling rates between 32 and 96 dpa as a function of rastering frequency. A frequency of zero corresponds to a defocused beam. 
Table 1 - Raster and defocused beam parameters including the duty factor, beam-on and beamoff times, and instantaneous and average dpa rates.

\begin{tabular}{|c|c|c|c|c|c|c|}
\hline & & Beam-On (s) & Beam-Off (s) & Duty Factor & $\begin{array}{l}\text { Instantaneous } \\
\text { dpa rate } \\
\text { when beam is } \\
\text { on }(\mathrm{dpa} / \mathrm{s})\end{array}$ & $\begin{array}{c}\text { Time-averaged } \\
\text { dpa rate } \\
\text { through the } \\
\text { whole } \\
\text { irradiation } \\
(\mathrm{dpa} / \mathrm{s})\end{array}$ \\
\hline \multirow{3}{*}{ Raster } & $15.63 \mathrm{~Hz}$ & 0.018 & 0.046 & \multirow{3}{*}{$28 \%$} & \multirow{3}{*}{$6.26 \mathrm{E}-3$} & \multirow{4}{*}{$1.74 \mathrm{E}-3$} \\
\hline & $1.95 \mathrm{~Hz}$ & 0.142 & 0.370 & & & \\
\hline & $0.244 \mathrm{~Hz}$ & 1.14 & 2.96 & & & \\
\hline \multicolumn{2}{|c|}{ Defocus } & - & - & $100 \%$ & $1.74 \mathrm{E}-3$ & \\
\hline
\end{tabular}


Table 2 - Void characteristics from the current study. Maximum void swelling and swelling at $600 \mathrm{~nm} \pm 100 \mathrm{~nm}$ below the surface are provided for each set of samples.

\begin{tabular}{|c|c|c|c|c|c|c|c|c|}
\hline & \multicolumn{4}{|c|}{50 peak DPA specimen } & \multicolumn{4}{|c|}{150 peak DPA specimen } \\
\hline & $\begin{array}{c}\text { Maximum } \\
\text { Void } \\
\text { Swelling } \\
(\%)\end{array}$ & $\begin{array}{c}\text { Void } \\
\text { Swelling } \\
\text { at } 600 \\
\text { nm (32 } \\
\text { dpa) }\end{array}$ & $\begin{array}{c}\text { Void } \\
\text { Density } \\
\left(10^{14} / \mathrm{cm}^{3}\right)\end{array}$ & $\begin{array}{l}\text { Average } \\
\text { Radius } \\
(\mathrm{nm})\end{array}$ & $\begin{array}{c}\text { Maximum } \\
\text { Void } \\
\text { Swelling } \\
(\%)\end{array}$ & $\begin{array}{l}\text { Void } \\
\text { Swelling } \\
\text { at } 600 \mathrm{~nm} \\
(96 \mathrm{dpa})\end{array}$ & $\begin{array}{c}\text { Void } \\
\text { Density } \\
\left(10^{14} / \mathrm{cm}^{3}\right)\end{array}$ & $\begin{array}{c}\text { Average } \\
\text { Radius } \\
\text { (nm) }\end{array}$ \\
\hline $\begin{array}{c}15.63 \\
\mathrm{~Hz}\end{array}$ & $0.19 \pm 0.02$ & $\begin{array}{l}0.05 \pm \\
0.005\end{array}$ & 4.79 & $14.2 \pm 3.3$ & $1.3 \pm 0.2$ & $1 \pm 0.21$ & 1.4 & $19.0 \pm 6.1$ \\
\hline $1.95 \mathrm{~Hz}$ & $0.92 \pm 0.12$ & 0 & 0.02 & $\begin{array}{c}12.4 \pm \\
4.83\end{array}$ & $5.5 \pm 1.3$ & $\begin{array}{c}2.06 \pm \\
1.25\end{array}$ & 0.746 & $\begin{array}{c}26.9 \pm \\
6.83\end{array}$ \\
\hline $\begin{array}{c}0.244 \\
\mathrm{~Hz}\end{array}$ & $0.78 \pm 0.05$ & $\begin{array}{c}0.42 \pm \\
0.03\end{array}$ & 496 & $6.5 \pm 3.22$ & $5.2 \pm 0.24$ & $\begin{array}{c}2.71 \pm \\
0.18\end{array}$ & 10.9 & $17 \pm 6.53$ \\
\hline Defocus & $1.32 \pm 0.06$ & $\begin{array}{c}0.81 \pm \\
0.08\end{array}$ & 42.5 & $\begin{array}{c}17.4 \pm \\
3.97\end{array}$ & $\begin{array}{c}12.0 \pm \\
0.81\end{array}$ & $\begin{array}{c}8.62 \pm \\
0.85\end{array}$ & 2.29 & $\begin{array}{c}31.6 \pm \\
10.2\end{array}$ \\
\hline
\end{tabular}




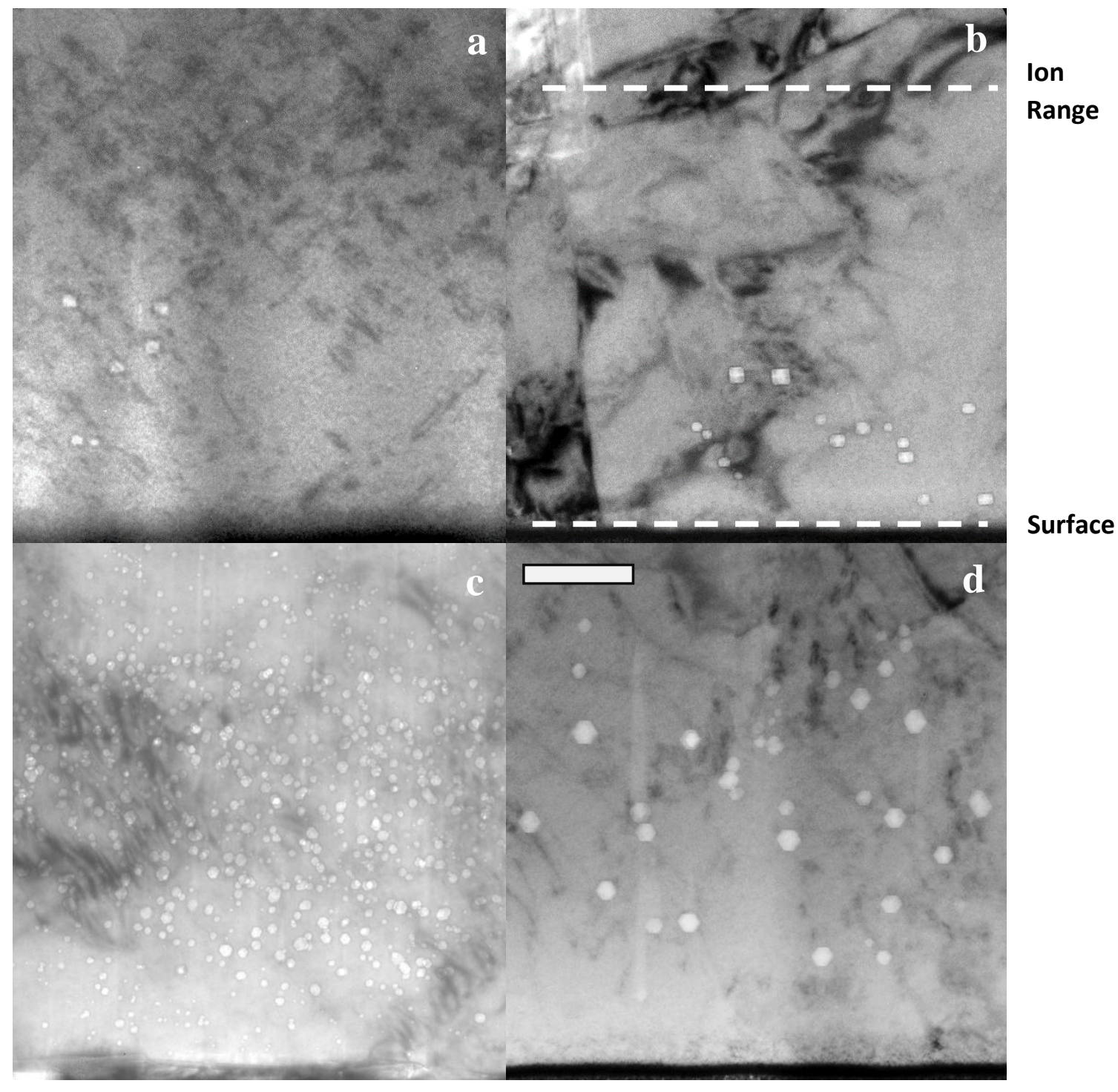

Figure 1 - Micrographs of void swelling for irradiation to 50 dpa at peak maximum in pure iron for rastered beams at. (a) $15.63 \mathrm{~Hz}$, (b) $1.95 \mathrm{~Hz}$, (c) $0.244 \mathrm{~Hz}$, and a (d) defocused beam. Length of the scale bar is $250 \mathrm{~nm}$. Dashed lines mark the surface and the incident ion range with the incident ion direction normal to the surface. 


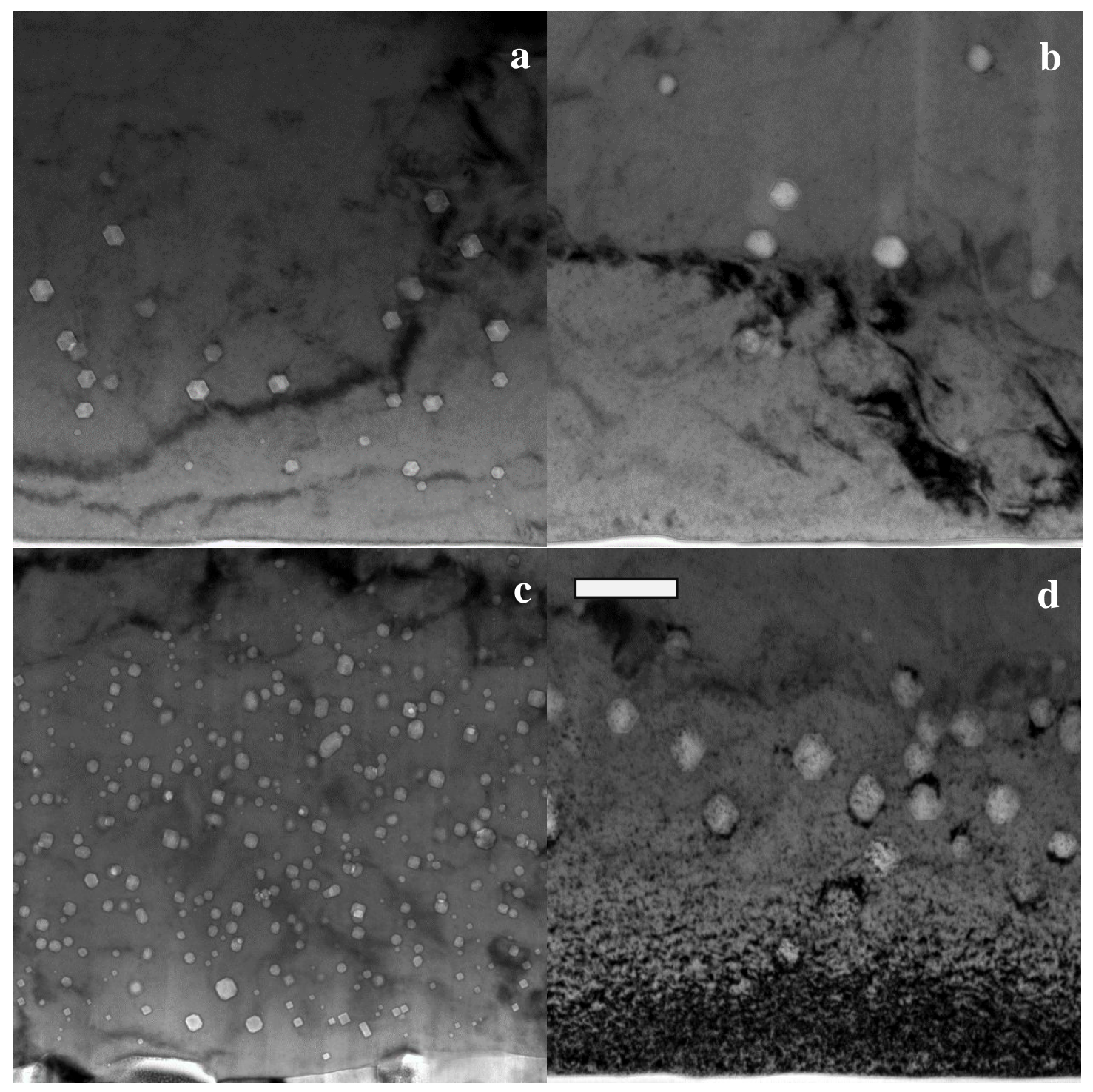

Figure 2 - Micrographs of void swelling for irradiation to 150 dpa at peak maximum in pure iron for rastered beams at (a) $15.63 \mathrm{~Hz}$, (b) $1.95 \mathrm{~Hz}$, (c) $0.244 \mathrm{~Hz}$, and with a (d) defocused beam condition. Length of the scale bar is $250 \mathrm{~nm}$. 


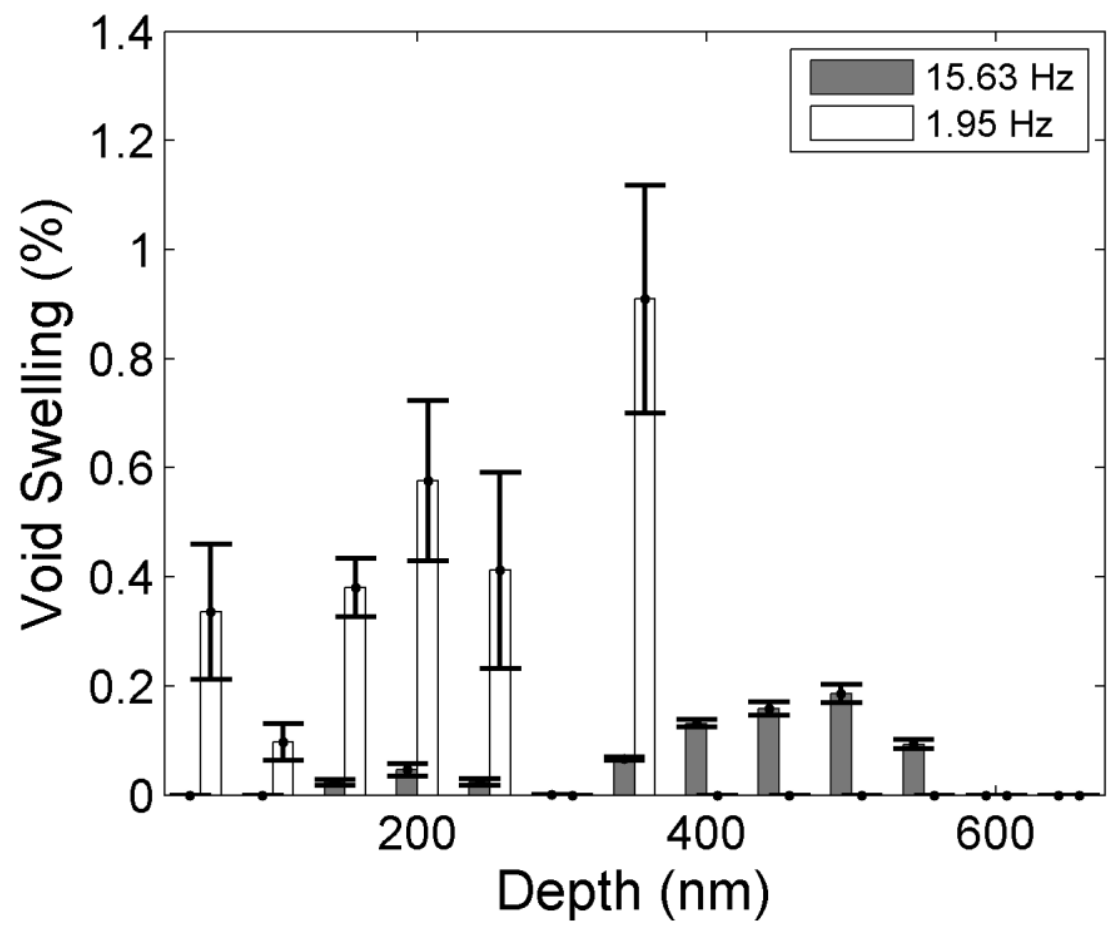

Figure 3 - Comparison of depth dependent swelling for 50 peak dpa irradiation with raster beam frequencies of $15.63 \mathrm{~Hz}$ and $1.95 \mathrm{~Hz}$. Swelling data represented by each bar averaged over a $50 \mathrm{~nm}$ depth. 


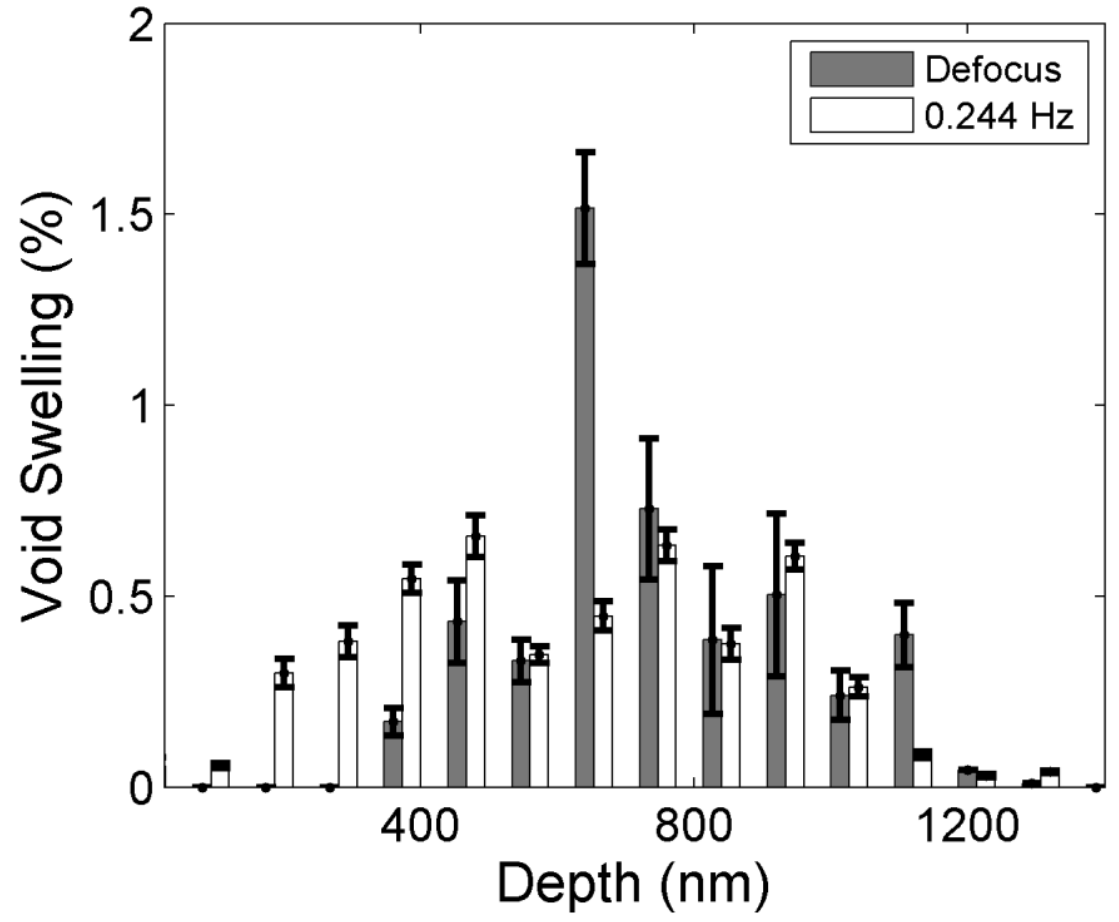

Figure 4 - Comparison of depth-dependent swelling for 50 peak dpa irradiation with defocused beam and raster beam frequency of $0.244 \mathrm{~Hz}$. Swelling data represented by each bar averaged over a $100 \mathrm{~nm}$ depth. 


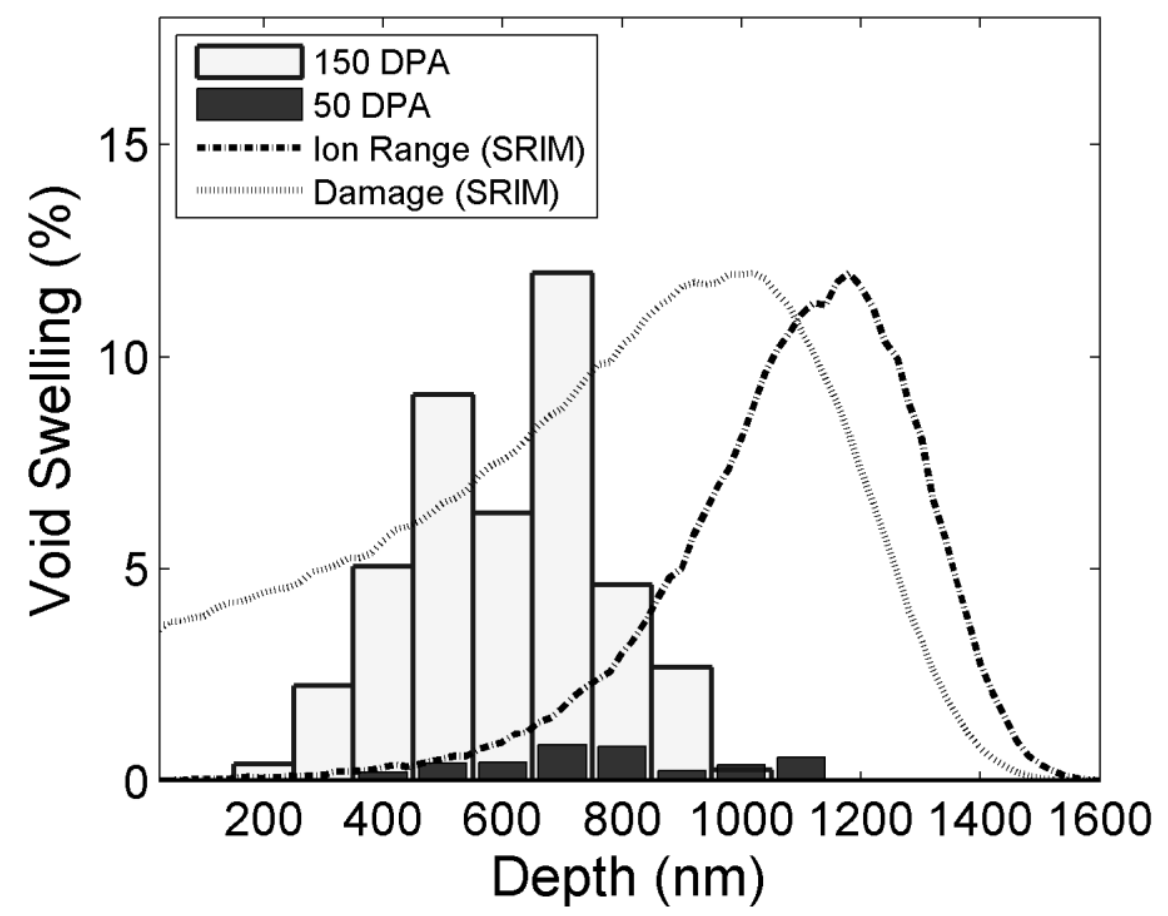

Figure 5 - Comparisons of depth-dependent swelling from a defocus beam for 50 and 150 peak dpa. Profiles of dpa and Fe implanted ion distributions from SRIM calculation are plotted for comparison. 


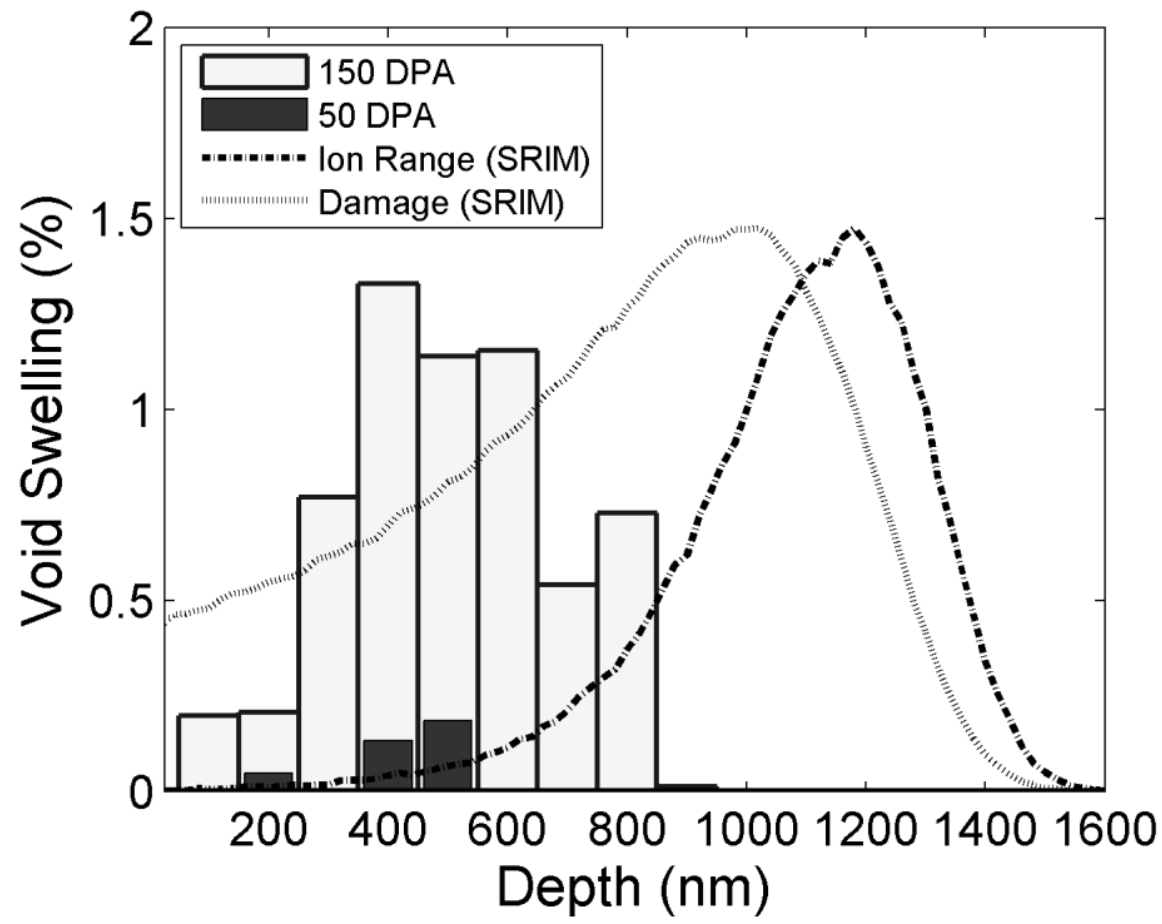

Figure 6 -Comparisons of depth-dependent swelling from a $15.63 \mathrm{~Hz}$ rastering beam for 50 and 150 peak dpa. Profiles of dpa and Fe implanted ion distributions from SRIM calculation are plotted for comparison. 


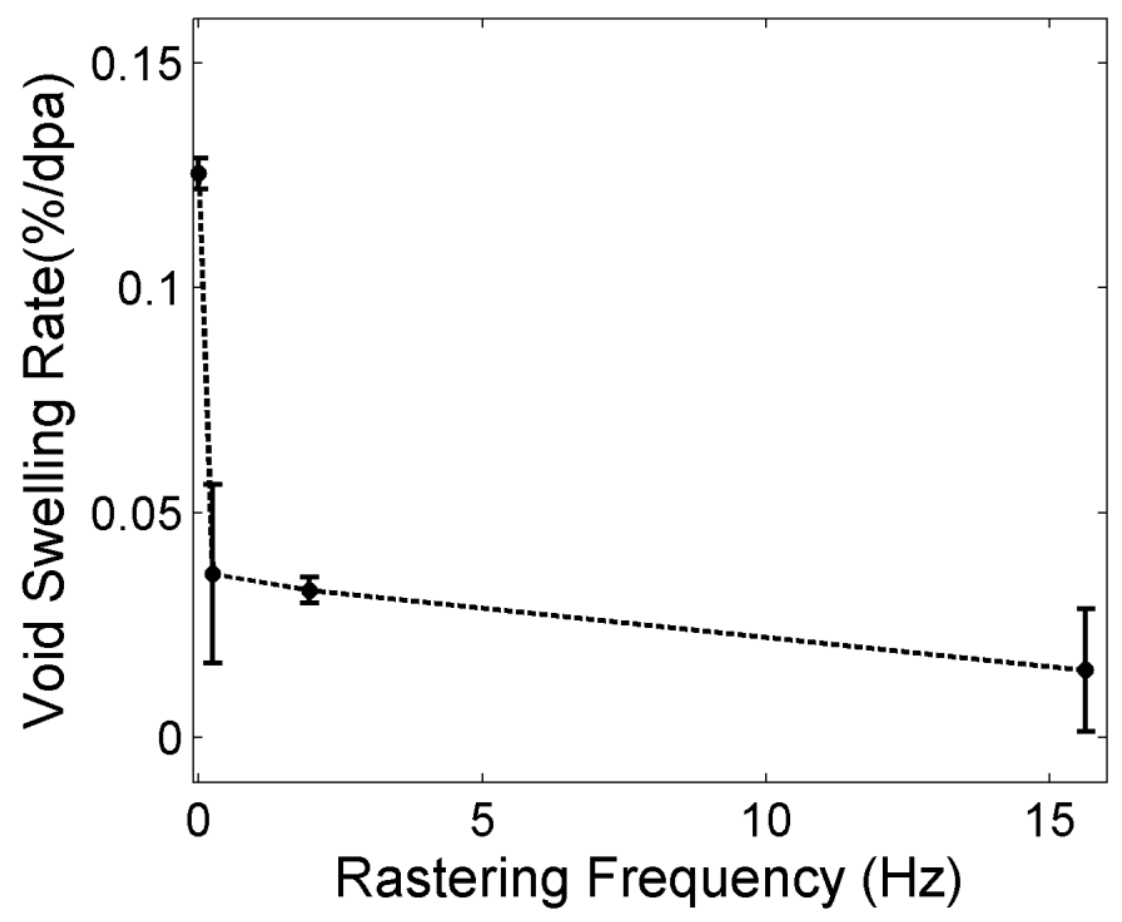

Figure 7 - Void swelling rates between 32 and 96 dpa as a function of rastering frequency. A frequency of zero corresponds to a defocused beam. 